Portland State University

PDXScholar

$1-1-2012$

\title{
The Lived Experience of High School Policy Debate in Oregon
}

Ameena AnnaMaria Amdahl-Mason

Portland State University

Follow this and additional works at: https://pdxscholar.library.pdx.edu/open_access_etds Let us know how access to this document benefits you.

\section{Recommended Citation}

Amdahl-Mason, Ameena AnnaMaria, "The Lived Experience of High School Policy Debate in Oregon" (2012). Dissertations and Theses. Paper 531.

https://doi.org/10.15760/etd.531

This Thesis is brought to you for free and open access. It has been accepted for inclusion in Dissertations and Theses by an authorized administrator of PDXScholar. Please contact us if we can make this document more accessible: pdxscholar@pdx.edu. 
The Lived Experience of High School Policy Debate in Oregon

by

Ameena AnnaMaria Amdahl-Mason

A thesis submitted in partial fulfillment of the requirements for the degree of

\author{
Master of Science \\ in \\ Communication
}

Thesis Committee:

Priya Kapoor, Chair

Susan Poulsen

Christopher Carey

Portland State University

(C)2012 


\begin{abstract}
This study seeks to explore the lived experience of competitors in high school level Oregon Style Cross-Examination Policy Debate in the state of Oregon. To elucidate this experience, between fifteen former competitors, graduating between 2003 and 2010, were interviewed in order to find common themes within the interviewees' experiences. The common themes that emerged from the interviews included establishing a knowledge base, the ability to research, effective use of communication skills, the development of confidence, and political awareness.
\end{abstract}




\section{Acknowledgements}

I would like to acknowledge all of my colleagues in the speech and debate community in

Oregon, who have supported me every step of the way, as well as my advisor, Dr. Priya

Kapoor, who never let me give up. 


\section{Table of Contents}

Acknowledgements .............................................................................................................. ii

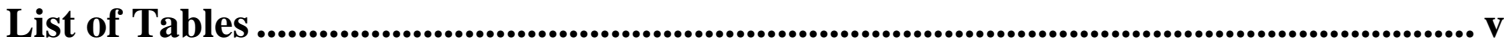

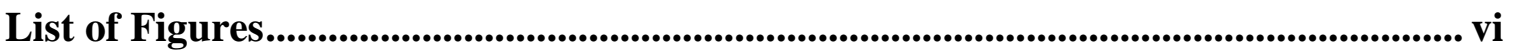

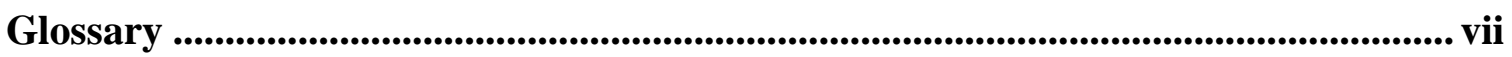

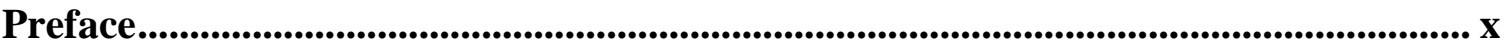

Chapter 1: Introduction .................................................................................................................. 1

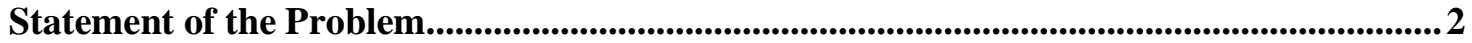

Theoretical Perspective .................................................................................................................2

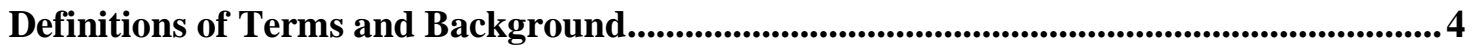

Chapter 2: Review of the Literature ......................................................................................... 11

Background Theory.............................................................................................................................11

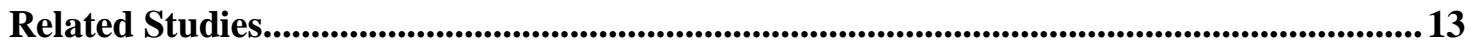

Chapter 3: Methodology................................................................................................. 20

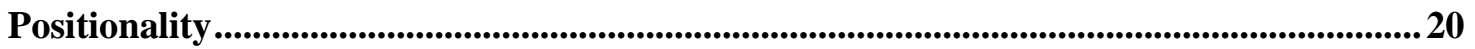

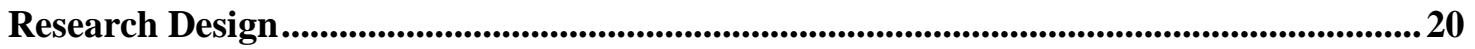

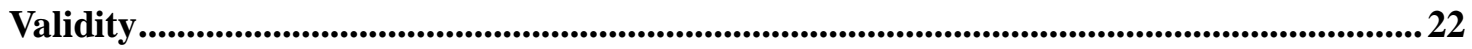

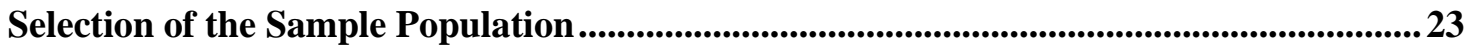

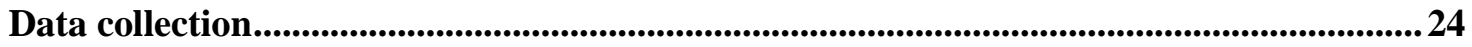

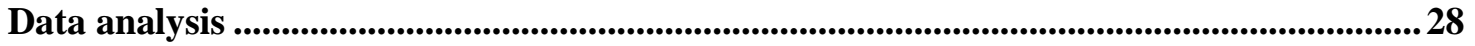

Chapter 4: Description of the Sample and Initial Thematization ............................ 31

The Description of the Sample ................................................................................................31

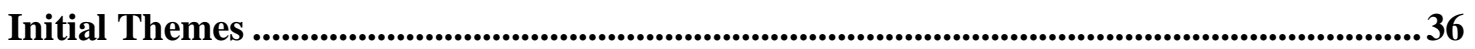

Theme One: Establishing a Knowledge Base ................................................................37

Theme Two: Effective Use of Communication Skills ..........................................................39

Theme Three: The Ability to Research ..........................................................................41

Theme Four: Development of Confidence..........................................................................4

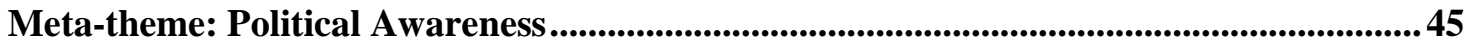

Chapter 5: Discussion and Conclusion ........................................................................... 48

Limitations of the Study ..................................................................................................................................52

Potential Topics for Future Study ........................................................................................................53

Significance of the Study ................................................................................................................................53 


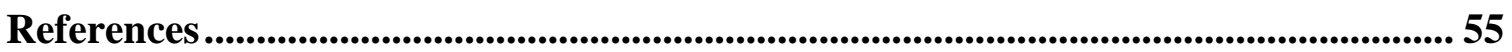

Appendix A: Informed Consent ........................................................................................... 61

Appendix B: Introductory Email ......................................................................... 62

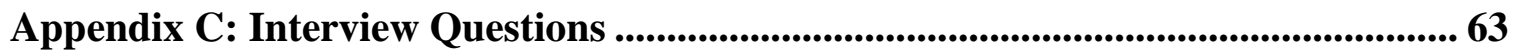

Appendix D: Topics Debated Between 1999-2010 ................................................ 65 


\section{List of Tables}

Table 1: The speeches in a Policy Debate round (Hanes, 2007, p. 12) .......................... 10

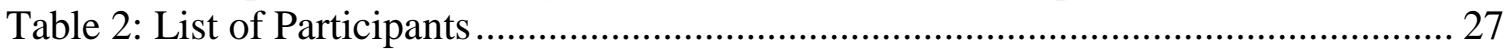




\section{List of Figures}

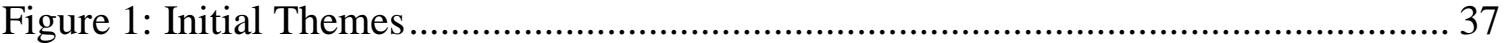




\section{Glossary}

Advantage: a part of the affirmative case read during the first affirmative speech, "a reason to take a course of action; to show a plan will offer a benefit" (Hanson, 1990, p. 4) communications judge: a judge with a communications paradigm, "a communications judge is less interested in the flow and more interested in persuasion" (Hanes, 2007, p. 65)

cross-examination: often called " $\mathrm{CX}$," it is "a question-and-answer period of a speaker by an opponent speaker" (Hanes, 2007, p. 10-11)

disadvantage: an argument presented by the negative, in opposition to the affirmative case, "a reason against taking a course of action; to show a plan will cause harm" (Hanson, 1990, p. 53)

first affirmative constructive (1AC): the first affirmative speech in a Policy Debate; the only completely pre-prepared speech; given by the first speaker on the affirmative team first affirmative rebuttal (1AR): the third affirmative speech in a Policy Debate; the sixth speech overall; often considered the hardest speech; given by the first speaker on the affirmative team first negative constructive (1NC): the first negative speech in a Policy Debate, the second speech overall; given by the first speaker on the negative team first negative rebuttal (1NR): the third negative speech in a Policy Debate, the fifth speech overall; forms the negative block the $2 \mathrm{NC}$; given by the first speaker on the negative team 
flow: the style of note-taking used in debate rounds, which can be used as a noun ("I used my flow to find where they made that response") or a verb ("I flowed that round really carefully"); these notes can be taken on paper or a computer harms: "claims about what in the status quo is bad" (Hanes, 2007, p. 83); one of the stock issues in Policy Debate

inherency: "the claim that the status quo will not be changed: the harm or harms identified will continue indefinitely" (Hanes, 2007, p. 83); one of the stock issues of Policy Debate

negative block: often called the "neg block," it is two back-to-back speeches by the negative team, for a total of thirteen minutes, split in the middle by a cross-examination period

paradigm: "the framework through which a judge evaluates a debate" (Hanes, 2007, p.

round: "one debate is called a round" (Hanes, 2007, p. 10)

run: "to argue; to support a position" (Hanson, 1990, p, 158); for example, "they are running United States hegemony is good" would mean, "they are arguing that United States hegemony is good"

second affirmative constructive (2AC): the final affirmative speech in a Policy Debate; the eighth and final speech overall; given by the second speaker on the affirmative team second negative constructive (2NC): the second negative speech in a Policy Debate, the fourth speech overall; forms the negative block with the 1NR; given by the second speaker on the negative team 
second negative rebuttal (2NR): the final negative speech in a Policy Debate; the seventh speech overall; given by the second speaker on the negative team significance: "the issue of whether there is an important problem and harms in the present system; the need for a plan" (Hanson, 1990, p. 165)

solvency: "the issue of whether a plan...will solve a problem, achieve an advantage, or meet a goal"' (Hanson, 1990, p. 166)

spread: "to present many arguments, usually at a rapid rate" (Hanson, 1990, p. 170) stock issues: the basic issues used to defend an affirmative case, usually harms, inherency, solvency, topicality, significance tab judge: a judge with a tabula rasa paradigm, who "describes him- or herself as a blank slate, waiting to be inscribed by your arguments" (Hanes, 2007, p. 65) topicality: "topicality is the name we give to any argument about whether the affirmative plan falls within the resolution. It is unlike the other stock issues in a key way: it is an either/or issue. Either the affirmative plan is topical, or it is not” (Hanes, 2007, p. 91) 


\section{Preface}

I started debating when I was sixteen years old, as a junior in high school. Two of my friends were Policy Debaters, and they told me that I would enjoy joining the speech and debate team, and that I would particularly enjoy Policy Debate. That first year, I debated the topic, Resolved: That the federal government should establish a program to substantially reduce juvenile crime in the United States, and I was hooked. In college, I competed in parliamentary style debate, and upon returning to Oregon, I began coaching speech and debate at the high school level, first at West Linn High School, and more recently at Clackamas High School. I coach many speaking and debate events, but my first love has always been Policy Debate. When picking a topic for my Communication thesis, I knew that I wanted to examine this style of debate. This thesis is an outcome of that exploration. 


\section{Chapter 1: Introduction}

Dewey (1903) noted that "modern life means democracy, democracy means freeing intelligence for independent effectiveness - the emancipation of mind as an individual organ to do its own work" (p. 193). Dewey considered inquiry and questioning to be a central part of an informed democratic citizenry, beginning in the elementary school years. Likewise, Freire argues that "education either functions as an instrument which is used to facilitate integration of the younger generation into the logic of the present system and bring about conformity or it becomes the practice of freedom, the means by which men and women deal critically and creatively with reality and discover how to participate in the transformation of their world" (p. 34). Within the current elementary and secondary education system, one area in which inquiry and questioning can be fostered is through the activity of high school-level competitive debate. This activity provides an extra-curricular and co-curricular method of fostering the ability to question and problem solve among youth. It provides a forum for questioning and pondering, for proposing solutions and arguing their relative merit. It allows students to consider the way in which specific plans of action would affect not only the issues that they seek to address, but also their effects on the world at large, examining the interdependence of our reality. It provides the opportunity for students to examine both sides of an issue, not just focus on the side to which they are initially drawn to the exclusion of examining the other side of the issue. It is the lived experience of this type of questioning and problem solving that this study seeks to examine, focusing on the 
experience of participation in Oregon-style Cross Examination Policy Debate, henceforth referred to as Policy Debate, at the high school level, as practiced in Oregon.

\section{Statement of the Problem}

Geren (2001) noted that Dewey considered education as a necessary component of public discourse, and he considered such public discourse to be "a learned activity which incorporates habits of inquiry, a socially directed emotional attachment, and an ability to suspend immediate action" (p. 196). Competitive debate provides a structured way for youth to engage in such inquiry. Specifically, Policy Debate provides an opportunity for high school aged students to engage in in-depth inquiry surrounding a specific topic area, with the possibility of examining that topic area from a variety of perspectives. Policy Debate is a switch side debate, forcing students to examine the merits of both sides of the issue. This study seeks to examine the way in which former competitors, who have graduated within the previous ten years, perceive the effects of their engagement with Policy Debate. Policy Debate has been chosen as a focus for this study, as opposed to studying all types of debate in Oregon, in order to create a more detailed perspective on the lived experience within a specific style of debate.

\section{Theoretical Perspective}

Turnbull (2008) noted, "Dewey allocated a central place to questioning but he situated questioning within an overall picture in which experience determined what counts as knowledge" (p. 57). This conception of knowledge leads to the use of phenomenology as a way to explore the issues central to the connections between democracy and debate. In contrast to an experimental or an ethnographic approach, "from 
a phenomenological point of view, to do research is always to question the way we experience the world, to want to know the world in which we live as human beings" (Van Manen 1990, p. 5). Phenomenology does not seek to provide a result that can be replicated, but rather, Van Manen (1990) observes, phenomenology is, in a broad sense, a philosophy or theory of the unique; it is interested in what is essentially not replaceable. We need to be reminded that in our desire to find out what is effective systematic intervention (from an experimental research point of view); we tend to forget the change we aim for may have different significance for different persons (p. 7).

This study uses phenomenology as it seeks to describe the lived experience with regard to the intersection of critical thinking, public discourse, and debate. Phenomenology allows the study to be a process of "exploring and gathering experiential narrative material that may serve as a resource for developing a richer and deeper phenomenon of human phenomenon" (Van Manen, 1990, p. 66), in this case the phenomenon of debate and public discourse. This study focuses on existential phenomenology, rather than transcendental phenomenology, as its goal is to examine concrete human experience in relation to the natural world, rather than to examine the nature of experience as outside of a relationship with the world at large.

Moustakas (1994) notes, “the empirical phenomenological approach involves a return to experience in order to obtain the comprehensive descriptions that provide the basis for a reflective structural analysis that portrays the essences of the experience" (p. 13). In this approach, there are two descriptive levels, with first being the collection the original data of descriptions gained through open-ended questions and dialogue, and the second, the analysis and interpretation on the part of the researcher. 
Aspers (2009) observes that in comparison to other social scientists' approach to their research, "the empirical phenomenologist wants to explore the world in a less predetermined way, reflecting actors' meaning structures rather than her own" (p. 8). This method, semi-structured interviewing, is a key facet of phenomenological research, and an important aspect of creating a shared vision of the participants' lived experience.

\section{Definitions of Terms and Background}

Debate itself draws upon the idea of rhetoric, first originated by the Greeks. Rhetoric is derived from the Greek word, rhetor, which means "a speaker, especially a speaker in public meeting or court of law" (Kennedy, 2007, p. 8). The idea of the art of public speaking, or rhetorike, first appeared in a datable text around 380 B.C.E. in Plato's dialogue, Gorgias. It was used by Plato and Aristotle in their liberal arts curriculum and was closely connected to the development of democracy in Greece. Aristotle adapted Plato's ideas about rhetoric for practical usage, based upon philosophical values and ideas; his text, On Rhetoric, seeks to describe what is universally true, with a focus on public address and civic discourse.

The idea of debate as an important part of education has continued throughout history, and it has been a part of education in the United States from the early days of debating societies and clubs in colleges and universities, and has been a facet of secondary education even before any formal governing organization existed. While high school level competitive debate in the United States varies from state to state, the majority of competitors and schools belong to the National Forensic League, a 
competitive speech and debate honor society founded in 1925 (National Forensic League, n.d).

The National Forensic League, which has run the National Speech Tournament every year since 1931, recognizes three forms of debate, Policy Debate, Lincoln-Douglas debate, and Public Forum debate (National Forensic League, n.d.). Each type of debate has specific rules laid out by the National Forensic League, which are strictly enforced at the National Speech Tournament, but can be modified by individual states for their state tournaments and by tournament hosts for invitational tournaments. A fourth type of debate, Public or parliamentary debate, is sponsored on the state level by the Oregon School Activities Association, but is not a competitive event sponsored by the National Forensic League.

In all forms of high school level competitive debate, two teams face one another, with one side affirming and the other side negating a resolution or statement. Competitors in all forms must come prepared to both affirm and negate, making all types of debate switch-side in nature, as debaters are not able to choose to support only one side of an issue. However, the types of debate each have different topic types and different expectations for presentation of the key ideas. This study focuses on Policy Debate, although other types of debates are referenced in the participants' lived experiences.

Policy Debate was the first style of debate sponsored by the National Forensic League, and it is "the oldest form of competitive debate in American high schools, dating from the early 1900s" (Edwards, 2008, p. 63). In this style of debate, two-person teams consider a single governmental policy based topic over the course of a school year. This 
topic is expressed in the form of an over-arching policy-based resolution, advocating specific action by the United States' federal government, such as "Resolved: The United States federal government should substantially increase alternative energy incentives in the United States." The selection of these topics is conducted by the National Federation of State High School Associations, a process through which "every high school sponsoring policy debate has an opportunity to influence the topic selection" (Edwards, 2008, p. 64). For the purpose of this study, Oregon-style Cross-Examination Policy Debate will be referred to as "Policy Debate," which is also the most common way to describe it in the Oregon speech and debate community, as well as nationally. In this style of debate, before each round of competition, one team is pre-assigned to affirm the resolution, while the other is assigned to negate it; every team will be expected to debate each side at least once over the course of a given debate tournament.

The affirmative team must present "a new policy that departs from the status quo, and defend the benefits of implementing the plan" (Hanes, 2007, p. 44). Examples of plans for the alternative energy resolution discussed above could include increasing solar photovoltaic cells through the incentive of increasing the production tax credit for solar power, or increasing ethanol usage through the incentive of an increased fuel standard. The affirmative team must show "why the present system cannot or will not resolve the problems cited in the affirmative case," in essence demonstrating that the government or other agencies will not enact the plan or solve the problem without the plan proposed by the affirmative (Edwards, 2008, p. 74). Additionally, this team must show that the plan solves the issues presented by the resolution, in this case the substantial increase of 
alternative energy. They must also show that there are advantages to the plan, which may be policy advantages such as decreased global warming or increased job opportunities, or philosophical advantages such as decreases in racism. The affirmative team has the presumption of fiat, or the "right of the affirmative to assume that its plan would be adopted in the political structure specified by the plan," rather than focusing on whether Congress would pass the plan or if the president would veto it (Edwards, 2008, p. 336).

The negating team's job is to negate, or disaffirm, the resolution, but they are "expected to respond specifically to the example of the resolution advanced in the affirmative case" (Edwards, 2008, p. 99). On a policy level, the negative team may present counterarguments for the plan's ability to solve the problem presented in the resolution, or they may show that the plan is in the process of being enacted in the status quo. The team may also present disadvantages to the plan, such as claiming that enacting the plan will cause issues within the United States' relations with other nations, issues with the United States economy, or issues related to politics in the United States. The negative team also has the option of creating a counterplan, or an alternative way of solving the problem stated in the resolution, such as funding the solution through nongovernmental means.

On a non-policy based level, the negative team can argue the topicality of the affirmative plan, arguing "the issue of whether the affirmative plan supports the resolution" (Hanson, 1990, p. 182). On the alternative energy topic, clean coal technology or nuclear energy might be argued not to be an alternative energy, but rather a mainstream energy technique, and therefore, the negative team would argue that the 
affirmative team was untopical, or did not fit within the bounds of the resolution. The negative team also has the option of proposing a kritik, or an argument that challenges a certain mindset, assumption, or discursive element that exists within the advocacy of the affirmative team, such as the use of sexist language or ethnocentric assumptions.

For both teams, the use of evidence, as well as organization of said evidence, is a very important aspect of Policy Debate. Each speaker is expected to present source citations for each of his or her arguments. Edwards (2008) notes that Policy Debate has been criticized for not developing public speaking skills, including eye contact, gestures, and vocal variety, while instead focusing on the idea that "judges award wins and losses based on the arguments presented and the evidence offered in support of those arguments" (p. 83). This is often manifested by very speedy delivery, sometimes called spreading, which might not be comprehensible to a non-debater. The ability to speak quickly is often valued by participants in competitive Policy Debate, and it may be a point of pride for competitors.

Due to the focus on argumentation in this style of debate, extensive research and preparation is the norm among Policy Debaters. Often students attend debate camps sponsored by colleges and universities during the summer months in order to prepare for the upcoming debate season. During the course of the year, there is a significant amount of ongoing research, as students must keep up to date about current events, and how they will affect the plan of action that they are advocating or plans which they will need to negate. This ongoing research can take place in the classroom, in groups meeting outside the classroom, in debate partner pairs, or individually. Often on a speech and debate team 
that is fielding several Policy Debate teams, different teams of two may take ownership of research for specific topics or lines of argumentation, and then report to the larger group, sharing evidence and ideas.

Policy Debate includes a significant amount of jargon, used both within the debate round and when describing aspects of the debate style. Specific pieces of evidence are referred to as "cards," dating back to the time when evidence was typed or written on note cards used in competition. Note taking among debaters is referred to as "flowing," and the ability to do this well is much prized. The lens or expectations through which a particular judge will adjudicate a debate round are called his or her "paradigms," and the expectation is that competitors will attempt to conform to these expectations.

In a given debate round, a specific format is always followed. The debate is designed to have equal speaking time for both sides, with a block of argumentation for the negative team (see Table 1). Each speech has a specific role. The first affirmative constructive (1 $\mathrm{AC})$ provides an overview of the plan proposed by the affirmative. The first negative constructive (1NC) provides the initial negative strategy. The second affirmative constructive (2AC) provides the affirmative the opportunity to refute the negative team's claims. The negative block (the $2 \mathrm{NC}$ and the $1 \mathrm{NR}$ ), allows the negative team to solidify which arguments they intend to pursue. The final three speeches, the first affirmative rebuttal (1AR), the second negative rebuttal (2NR), and the second affirmative rebuttal (2AR), provide the summary of the benefits of each side, respectively, and the detractions of their opponent's side. 


\begin{tabular}{|c|c|c|c|c|}
\hline \multicolumn{2}{|c|}{ AFFIRMATIVE } & \multirow{2}{*}{ TIME } & \multicolumn{2}{|c|}{ NEGATIVE } \\
\hline $1^{\text {st }}$ SPKR & $2^{\text {nd }} S P K R$ & & $1^{\text {st }}$ SPKR & $2^{\text {nd }} S P K R$ \\
\hline $1 \mathrm{AC}$ & & 8 mins & & \\
\hline \multirow[t]{2}{*}{ CXee } & & 3 mins & & CXer \\
\hline & & 8 mins & $1 \mathrm{NC}$ & \\
\hline \multirow[t]{6}{*}{ CXer } & & 3 mins & CXee & \\
\hline & $2 A C$ & 8 mins & & \\
\hline & CXee & 3 mins & CXer & \\
\hline & & 8 mins & & $2 \mathrm{NC}$ \\
\hline & CXer & 3 mins & & CXee \\
\hline & & 5 mins & $1 \mathrm{NR}$ & \\
\hline \multirow[t]{3}{*}{$1 \mathrm{AR}$} & & 5 mins & & \\
\hline & & 5 mins & & $2 N R$ \\
\hline & 2AR & 5 mins & & \\
\hline
\end{tabular}

Table 1: The speeches in a Policy Debate round (Hanes, 2007, p. 12)

In Oregon, the number of Policy Debate teams at a given speech and debate tournament is generally relatively small, often fewer than twenty teams total. As a result, an added dimension of Policy Debate in Oregon is a degree of familiarity with other teams, including their preferred arguments, their speaking styles, and their strengths and weaknesses. In addition, most Policy Debate teams in Oregon have a working knowledge of many of the coaches and other judges who often judge Policy Debate, allowing them to tailor their arguments to fit the paradigms of their judges. 


\section{Chapter 2: Review of the Literature}

\section{Background Theory}

Dewey considered the mediums of speaking and listening to be an important component of democracy, and "the act of communication is just that - activity. The difference between watching and speaking is the difference between being a spectator and a participant" (Whipple, 2005, p. 161). Participation in competitive debate is a form of participating in communication, and engaging in the inquiry and questioning associated with it. Dewey considered inquiry as something which should be taught to children as a form of problem solving, noting that "politics are a form of public problem solving: a practical activity in the service of certain goals" (Hildreth, 2009, p. 781). This communication is the basis for an active democracy. Participation in competitive debate can provide the venue for students to practice the problem solving skills related to politics, including the implications of political decisions.

However, Giroux (1997) argues that "both radical and conservatives alike have abandoned the Deweyian vision of public schools as democratic spheres, as places where the skills of democracy can be practiced, debated, and analyzed" (p. 119). He argues that a radical pedagogy, drawing on the work of Bahktin and Freire, is necessary. This radical pedagogy, he argues, "points to the need to develop a theory of politics and culture that analyzes discourse and voice as a continually shifting balance of resources and practices in the struggle over specific ways of naming, organizing, and experiencing social reality" (Giroux, 1997, p. 134-135). Debate is one of the ways in which such a radical pedagogy may be pursued. Through the analysis of both the political and philosophical issues 
related to a current events topic, and in considering the application of potential solutions in the world, debate allows for students to participate in the analysis of discourse and examine the balance of voices and resources existing within our current reality, potentially reinvigorating the Deweyian idea of schooling as a sphere in which democracy can be fostered.

The importance of democracy is echoed by Geren (2001), who notes that in the view espoused by Habermas, "genuine communication is the lifeblood of democracy. Modern societies are not static, and discursive rationality is the primary way societies can adapt and remain healthy" (p. 196). Drawing from critical theory and American pragmatism, Habermas considered that communicative interactions, or rational-critical debate, must play a central role in the public sphere. In his analysis of the invigoration of public life and democratic communication, Habermas developed two levels of society, the level of the system and the level of the lifeworld (Whipple, 2005). Habermas saw the boundaries between the two as "the system, defined by purposive reality, consists of the state and economy; the lifeworld, characterized by communicative rationality, consists of the private spheres (family, neighborhood, voluntary and civic associations) and public sphere (citizen life)" (Whipple, 2005, p. 167). Within the forum of Policy Debate, students have the ability to communicate within the lifeworld, most particularly regarding the public sphere. Practice in this level of communication as students can provide the basis for such communication as adults, whether or not students opt to exercise their communication skills as adults. 


\section{Related Studies}

Littlefield (2001) analyzed student perceptions of the effects of participation in Policy Debate and Lincoln-Douglas debate. He surveyed participants in debate at the 2001 National Forensic League National Tournament, using a self-selection method, allowing any student who was participating in a debate to participate in his survey. His survey included fifteen items, including significant demographic data about debate experience, gender, and geographic region; he focused on the data collected from the final two questions, which were open-ended. These questions were "IIdentify three perceived benefits gained by participation in debate' (Question 14) and 'identify three perceived disadvantages resulting from participation in debate' (Question 15)" (Littlefield, 2001, p. 85).

Littlefield used the students' free responses to construct ten broad categories for both the benefits and the disadvantages that the students perceived. Beginning with the most often reported, the benefits were communication/speaking skills, knowledge/education, social life/meet people, research skills, self-confidence/handle stress, critical/analytical skills, argumentation skills, thinking fast, improved relational communication/teamwork, and college admission. The disadvantages, in order of most often reported were that it takes time from other things/trade-off with other interests or activities, significant time commitment, causes stress/tension, no social life/isolation, fosters unhealthy habits/choices, costly/expensive, negative stigma by others, perception/criticism of self and other debaters, competition/politics/judging issues, critical of the nature of the debate activity. Littlefield's analysis focused on the ways in 
which these perceived advantages and disadvantages compare with the perceptions of collegiate debaters regarding the same issues, and suggested further study of the culture that debaters create for themselves and the ways in which coaches and teachers can help debaters minimize the disadvantages. Several of the advantages that Littlefield notes, including communication/speaking skills, knowledge/education, research skills, critical/analytical skills, argumentation skills, thinking fast, and improved relational communication/teamwork, clearly connect to the idea of debate as inquiry and a type of public problem solving and discourse.

Fine (2000) noted that "One arena in which adolescents confront discourse on social problems is high school policy debate: a school-sponsored contest in which teams of adolescents compete in tournaments where they are evaluated on their ability to engage in claims-making" (p. 104). Fine argued that participation in debate provides an opportunity to practice political discourse. He noted that "debate models social problems discourse as a competitive game and provides adolescents with the opportunity to acquire skills necessary for participation in policy arenas" (Fine, 2000, p. 104).

Fine provided extensive discussion of the types of argumentation and evidence in high school debate, using an ethnographic method, for which he followed two high school debate teams for a year. With a focus on debate as a game, contending that debate is an activity that must be taught, as the habits of argumentation are not part of a student's normal education, Fine provided discussion of how debaters must contend with the issues of which arguments they believe in, which they can support, and how these arguments fit into various frameworks for viewing a particular issue. He observed 
The willingness of debaters to cull empirical claims to support a position, bracketing their beliefs, is consistent with institutional ideals. Adolescents learn that the game framework provides a cultural model with winners and losers and that social policies should be constructed by organizing "facts" in a meaningful context (Fine, 2000, p. 120).

This analysis connects with the idea of debate as a way of fostering students' later participation within the public sphere. Fine acknowledged the interaction between the communicative aspect of debate and the construction of arguments as central to the way in which students are affected by participation in the activity, leading to a stronger ability to construct logical argumentation based upon evidence and analysis.

Greenstreet (1993) observed that "while most contemporary debate texts claim study of and/or experience in debate enhances the critical thinking skills of practitioners, little empirical evidence exists in support of that claim" (p. 13). Greenfield argued that much of the research on the connection between critical thinking and debate does not take into account the natural maturation that occurs during the high school years, and the lack of empiricism in the data. He also noted that much of the research was not current and did not reflect current practices, although he did not discount that future studies could indicate a relationship. Greenstreet does not disagree with the idea that those who participated in debate perceived benefits, but rather questioned the causality of these benefits.

Allen, Berkowitz, Hunt, and Louden's (1999) study used the process of metaanalysis of previous studies to examine the impact of forensics on critical thinking, focusing on studies which were quantitative, included some type of communication improvement exercise, such as competitive forensics or a forensics class, and some 
method of measuring critical thinking improvement (p. 21). Allen et al (1999) conclude, based on the quantitative analysis of their data, that "participation in public communication skill building exercises consistently improved critical thinking" (p. 27). While Allen et al did not focus on Policy Debate specifically, their study showed broadly the benefits of participation in public speaking activities. Post-dating Greenfield, their meta-analysis fills some of the gaps discussed by Greenfield.

Dyer (2004) applied the idea of scarcity theory, or the idea that any commodity, including intangible ones such as teachable skills, gains desirability due to scarcity (p. 15). While Dyer's work was focused on the undergraduate forensic experience, her observations are applicable to the high school level as well. She observed that in addition to critical thinking and speaking ability, participation in forensics also fosters skills such as "research, organization, time management, professionalism, dedication to practice, and effective use of instruction" (p. 16), along with the social skills of teamwork, adaptation to varied situations, and collegiality. These skills, when garnered in high school, provide a benefit to the participant in terms of being able to research and understand pertinent issues as an adult, and a member of society.

Dyer (2004) also asserted that the dedication of forensic students and the competitive nature of the activity often devalues the skills that students have learned, as "in forensic competition, repeated speaking becomes so routine in the performing culture that the repetition is taken for granted-unremarkable, except as an explanation for the end of day exhaustion" (p. 16). However, these skills when applied outside of the competitive arena are more valuable and applicable than the scores received in 
competition might show. Even an average forensic competitor has an advantage over students with no forensic experience.

Tumposky (2004) examines the issue of debate from within the context of education, noting that its continued use in classroom education beyond public speaking courses is "partly attributed to its association with two powerful concepts: critical thinking and democracy" (p. 52). However, Tumposky questions whether the competitive nature of debate makes it suited to a classroom setting, where louder, more persuasive students may overshadow their more timid counterparts. Tumposky's concern is less relevant in the context of competitive debate, which is, by its nature, a selfselecting activity. However, the benefits of critical thinking that she observed remain.

Turner, Yao, Baker, Goodman, and Materese (2010) conducted an experiment "to examine the conditions under which people are likely to examine information that is counter-attitudinal"' (p. 227). Participants were asked to prepare to either write an argumentative letter to the editor or prepare to debate another participant face-to-face. In preparation, they were allowed to conduct as much research as they wanted on both sides of the issue. Turner et al argued that confidence and expected interaction play a role in whether or not participants prepared for both sides of the topic they were arguing. They noted, "lay arguers tend to engage in arguing in social situations. When individuals anticipate a social encounter, communicative and functional goals are particularly salient" (p. 228). The experiment revealed, "when lay arguers are not forewarned, gathering opposing information appears unnecessary" (p. 236). While Turner et al do not directly contrast these results with debaters, the very nature of the activity of competitive 
debate necessarily promotes preparation on both sides of an issue. This preparation alleviates the issues of one-sided understanding of an issue, allowing for greater understanding of a topic from multiple perspectives.

The issue of preparation on both sides of a topic is discussed by Muir (1993), who notes that debate is "intended to teach debaters to see both sides of an issue and to become proficient in the exposition of argument... to present the best case possible given the issues they have to work with" (p. 278). Muir specifically referenced the focus that Dewey placed on reasoning in human development and the process of interaction that allowed the development of individual convictions. Muir (1993) noted that "the melding of different areas of knowledge, however, is a particular benefit of debate as it addresses topics of considerable importance in a real world setting... energy policy, prison reform, care for the elderly, trade policy, homelessness, and the right to privacy" (p. 284). This argument seeks to refute the charge that preparation for both sides of the issue leads to moral relativism, noting that the respect and acknowledgement of divergent views allows for greater tolerance and education.

These studies' analysis of the benefits perceived by students and the interaction between debate and public policy analysis provide a backdrop for further examination of the way in which debate as an activity connects to the emancipation of the mind that Dewey advocates. Dewey (1903) notes that in education there is a "tendency to reduce the activity of mind to a docile or passive taking in of the material presented" (p. 201); debate provides an opportunity for inquiry and problem solving, which this study seeks to explore further. In the previously discussed studies, many benefits have been discussed 
quantitatively; this study seeks to examine more particularly the human experience of participation in Policy Debate. 


\section{Chapter 3: Methodology}

\section{Positionality}

My interest in policy debate began with my own participation in high school. After college, as a new teacher, I was hired to coach a high school speech and debate team, a job that I have continued for more than ten years. Since then, participation in policy debate has declined in number in Oregon, although speech and debate overall has not. As an educator and coach, I believe that participation in speech and debate is valuable for high school students, as it allows them to develop critical thinking skills, research skills, presentation skills, and writing skills (Edwards, 2008; Fine, 2001). I also consider policy debate specifically to be a valuable style of debate, as it provides the opportunity for extensive research on a single topic over the course of a year. It is with these predispositions that I have examined the lived experience of high school policy debate in Oregon. In my professional life, I have observed both the positives and the negatives of participation in high school policy debate, but I continue to believe the positives outweigh the negatives.

\section{Research Design}

Van Manen (1990) noted, "lived experience is the starting and end point of phenomenological research. The aim of phenomenology is to transform lived experience into a textual expression of its essence" (p. 36). In order to create a textual expression of lived experience, the research was recorded in the form of recorded interviews, in order to "yield direct quotations from people about their experiences, opinions, feelings, and knowledge" (Patton, 2002, p. 4). The technique of asking about specific instances and 
experiences was used to draw out the lived experiences of former competitors in order to examine the themes that existed within their experiences, and how these experiences affected their lives after participation in high school Policy Debate. This design will serve what Moustakas (1994) describes as the goal of empirical phenomenology, noting that "the aim is to determine what an experience means for the persons who have the experience and are able to provide a comprehensive description of it" (p. 13). All of the participants are former high school Policy Debaters, and each was able to provide an idea of what the experience meant to them.

Additionally, Van Manen (1990) notes several potential concerns for those researching lived experience, including the effect on the people with whom the research is concerned, the effect on institutions where the research is conducted, the effect on the subjects or participants in the research, and the effect upon the researcher. Van Manen (1990) observes, "intense conversational interviews may lead to new levels of selfawareness...but if done badly, these methods may lead to feelings of anger, disgust, defeat, intolerance, insensitivity, etc." (p. 162-163). Due to these potential harms, the selection and interview process was done with much to care to ensure that participants are valued, honored, and respected throughout the study. My own status as a coach, for many participants a recognizable member of the Oregon speech and debate community, provided a sense of continuity for many of the participants. Although some did relive stressful or difficult memories, those participants were able to reflect upon their experiences and look upon them with new awareness. Many participants were pleased to recall their experiences, and consider the place those experiences held in their lives. As 
Nelson (1989) described the relationship of the researcher and participant in phenomenology by noting, "the interviewer/interviewee structure is replaced by the practice of co-researchers" (p. 227); this model was the basis for the interviewing conducted in this study.

Phenomenology as a method allows for an understanding of the lived experience of individuals, in contrast to a quantitative method that would provide a statistical analysis of experiences (Patton, 2002). Phenomenology as a method makes "more readily accessible the lived meanings as they are experienced by persons in situations as the primary data for analysis" (Nelson, 1987, p. 315). This study seeks to examine these meanings in order to analyze the similarities in the lived experience of high school Policy Debate in Oregon between 1999 and 2010. It does not seek to create a study that is replicable in the manner of quantitative analysis, but rather an understanding of the phenomena (Patton, 2002; Moustakas, 1994; Van Manen, 1990).

\section{Validity}

Validity in quantitative studies can be proven through statistical regression, but in a qualitative context, validity is viewed in a different light (Patton, 2002). Rather than being accountable to a statistical analysis, the phenomenological researcher is accountable to the community in which the study takes place (Creswell, 1998). In this study, I am not only accountable to the participants in the study, some of whom have expressed an interest in reading this thesis, but also to the greater speech and debate community in Oregon, as I expect the results of the study to be of interest to many of my colleagues. This type of accountability is different from the statistical forms of reliability 
used in quantitative methods. As Patton (2002) observed, "The validity, meaningfulness, and insights generated from qualitative inquiry have more to do with the information richness of the cases selected" (p. 245). The use of interviews to elucidate the lived experience of the participants allowed for a rich picture of human experience of these individuals. As Polkinghorne (2009) noted, "narrative researchers undertake their inquiries to have something to say to their readers about the human condition" (p. 476). It is this comment on the human condition that the study seeks to provide, rather than a numerically based analysis of commonality.

\section{Selection of the Sample Population}

Competitive Speech, an over-arching designation for both Speech and Debate, is an activity sanctioned by the Oregon School Activities Association (OSAA), which also oversees Band/Orchestra, Baseball, Basketball, Cheerleading, Choir, Cross Country, Dance/Drill, Football, Golf, Soccer, Softball, Solo Music, Swimming, Tennis, Track \& Field, Volleyball, and Wrestling. There are currently around ninety schools active in competitive Speech and Debate in Oregon, with sixty-five schools and more than 450 students competing at the OSAA Speech and Debate State Championship tournament in 2012 (Oregon Schools Activities Association, 2012) . The participants in this study are former competitors in Policy Debate from the schools who participated in competitive speech and debate, chosen through purposeful selection of competitors within ten years of high school graduation. This is a form of criterion sampling, appropriate to phenomenological research, as all participants must have the same lived experience (Patton, 2002). 
Policy Debate is an ever-changing activity, as the norms of the activity bend to the available technology and current trends. As this piece of research is a master's thesis, the age of the most recently graduated former competitors, up to ten years out of high school, have been chosen to provide a base understanding of lived experience, which could be followed up in future studies with additional age groups. This allows for the lived experiences of the participant to overlap and can be used to draw a somewhat broader picture of the experiences of competitors in that particular period.

In order to select a pool of potential participants, coaches from the ninety active schools were contacted to determine possible alumni who might be willing to participate in the study, and information was made available to recent graduates at local speech and debate tournaments. This process garnered a total of eighteen potential participants. The original goal was to interview between fifteen and twenty participants, so there was no need to use a narrowing process to select the interviewees. Of the eighteen potential interviewees, fifteen were interviewed. The remaining three potential interviews were unable to be interviewed for logistical reasons, including the demands of their current educational programs, although they remained interested in the content of the study.

\section{Data collection}

Following the tenets of phenomenology, the data were collected through one-onone interviews of the participants. This study used interviews as "a means for exploring and gathering experiential narrative material that may serve as a resource for developing a richer and deeper understanding of a human phenomena" (Van Manen 1990, p. 66). In order to provide an accurate record of the interviews, these interviews were taped using 
an MP3 recorder, in addition to notes recorded by the researcher during the interviews. Two years after the completion of the thesis, these recordings will be destroyed.

During the course of the study, each potential participant was provided with the informed consent form shown in Appendix A, and was initially contacted using the introductory email in Appendix B, if the introduction took place over email. For several of the interviewees, the initial contact was made in person. In those cases, the potential participants were provided with both the introductory email, in print form, and the informed consent form. All interviewees were provided the opportunity to withdraw at any time if they so desired. The interviewees all understood that their interviews would be confidential, but not anonymous. This procedure was approved by the Portland State University Human Subjects Research Review Committee (HSRRC),

The goal of these interviews was to provide a description of the former competitors lived experiences with participation in Policy Debate, and the way in which participation in Policy Debate connects to inquiry, analysis, and participation in the public sphere. Questions focused on the lived experience of the individual, providing specific details about said lived experience (see Appendix C for specific questions used), using questions approved by the Portland State University Human Subjects Research Review Committee (HSRRC). During the course of the interview, there was the flexibility for questions to be removed depending on the nature of the conversation. Most of the interviews contained nearly all of the questions in Appendix C, although in a few cases, some of the questions were unnecessary. For example, if a student told me that they never used philosophical arguments, I did not pursue further questions about their 
research methods for philosophical arguments.

In order to find participants who met the qualifications for my criterion based sampling, initially I contacted all of the current speech and debate coaches in Oregon to ask them to provide me with names and contact information for potential participants. As a coach in Oregon, I was able to email the webmaster for the Oregon High School Speech League Coaches' Association, and he sent the email to his official list of all active coaches. This initial email garnered six potential participants, who contacted me through email. I made contact with them, and four of the six were interviewed. After that, I posted information at several local debate tournaments, garnering five more potential participants, four of whom were interviewed. The remaining seven participants were referred by their coaches or other members of the Oregon speech and debate community.

The majority of the interviews took place in coffee shops, with a few taking place at debate tournaments or local universities, and one taking place at the conference room at the school where I work. There was some background noise in a few of the interviews, but it did not affect the interaction or the recording. Table 2 provides detailed information about the participants in relation to data collection. The choice was made to assign numbers to the students and letters to the high schools in order to not trivialize their experience with pseudonyms. The use of pseudonyms could pre-dispose the reader toward a specific perception of the participants, one that was not warranted by the data. 


\begin{tabular}{|c|c|c|c|c|c|}
\hline Participant & Gender & School & $\begin{array}{l}\text { Years in High } \\
\text { School }\end{array}$ & $\begin{array}{l}\text { Interview } \\
\text { Date }\end{array}$ & \begin{tabular}{|l|} 
Interview \\
Location
\end{tabular} \\
\hline Student 1 & male & $\mathrm{D}$ & $2002-2006$ & $\begin{array}{l}\text { November } \\
21,2011\end{array}$ & Coffee shop \\
\hline Student 2 & male & $\mathrm{H}$ & $2005-2009$ & $\begin{array}{l}\text { December } \\
28,2011\end{array}$ & Coffee shop \\
\hline Student 3 & male & $\mathrm{K}$ & $2006-2010$ & $\begin{array}{l}\text { December } \\
19,2011\end{array}$ & Coffee shop \\
\hline Student 4 & female & $\mathrm{C}$ & $2002-2006$ & $\begin{array}{l}\text { December } \\
28,2011\end{array}$ & Coffee shop \\
\hline Student 5 & male & $\mathrm{C}$ & 2003-2007 & $\begin{array}{l}\text { March 11, } \\
2012\end{array}$ & Skype \\
\hline Student 6 & male & $\mathrm{G}$ & $2005-2009$ & $\begin{array}{l}\text { March 23, } \\
2012\end{array}$ & \begin{tabular}{|l} 
Debate \\
tournament at a \\
local college \\
\end{tabular} \\
\hline Student 7 & male & A & 1999-2003 & $\begin{array}{l}\text { March 23, } \\
2012\end{array}$ & $\begin{array}{l}\text { Debate } \\
\text { tournament at a } \\
\text { local college }\end{array}$ \\
\hline Student 8 & male & $E$ & $2003-2007$ & $\begin{array}{l}\text { March 30, } \\
2012\end{array}$ & Coffee shop \\
\hline Student 9 & female & $\mathrm{B}$ & $2001-2005$ & $\begin{array}{l}\text { March 30, } \\
2012\end{array}$ & Coffee shop \\
\hline Student 10 & male & $\mathrm{B}$ & $2000-2004$ & $\begin{array}{l}\text { March 30, } \\
2012\end{array}$ & Coffee shop \\
\hline Student 11 & male & $\mathrm{F}$ & $2003-2007$ & $\begin{array}{l}\text { April 2, } \\
2012\end{array}$ & $\begin{array}{l}\text { Conference } \\
\text { room at the } \\
\text { school where I } \\
\text { work }\end{array}$ \\
\hline Student 12 & female & $\mathrm{C}$ & $2001-2005$ & $\begin{array}{l}\text { April 4, } \\
2012\end{array}$ & $\begin{array}{l}\text { Common area at } \\
\text { a local college }\end{array}$ \\
\hline Student 13 & male & $\mathrm{C}$ & 2003-2007 & $\begin{array}{l}\text { April 26, } \\
2012\end{array}$ & $\begin{array}{l}\text { Common area at } \\
\text { a local college }\end{array}$ \\
\hline Student 14 & male & I & $2005-2009$ & $\begin{array}{l}\text { April 26, } \\
2012\end{array}$ & Skype \\
\hline Student 15 & female & $\mathrm{J}$ & $2006-2010$ & $\begin{array}{l}\text { April 27, } \\
2012\end{array}$ & Skype \\
\hline
\end{tabular}

\section{Table 2: List of Participants}

All of the interviews were recorded using an MP3 recorder, in order to record the interview in its entirety. As Patton (2002) observed, "the raw data of interviews are the 
actual quotations spoken by interviewees. Nothing can substitute for these data; the actual things said by real people" (p. 380). During the interviews, I also took notes on the participants responses using an interview protocol, or "predetermined sheet on which one logs information learned during the observation or interview" (Creswell, 1998, p. 126). This protocol listed all of the questions in Appendix C, appropriately spaced to record responses, along with a header to note the name, school, graduation year, and years competed for the specific participant (Creswell, 1998).

Each interview was transcribed in its entirety, in order to aid in the analysis of the data. I chose to conduct all of the transcription myself in order to better understand the data. As Nelson (1989) noted "it is during the labor of transcribing that the researcher performs the actual transformation from the listening to speech to the writing of speech, of making visible the invisible" (p. 229). The process of transcription took between ninety minutes and one hundred and twenty minutes per transcription. The transcriptions, single-spaced in a twelve-point font, ranged from six pages to eleven pages, for a total of one hundred and twenty pages of transcription.

\section{Data analysis}

The purpose of a phenomenological study is to grasp the essential meaning of a phenomenon. Van Manen (1990) observes that in order to grasp this meaning, "it is helpful to think of the phenomenon described in the text as approachable in terms of meaning units, structures of meaning, or themes" (p. 78). The process of analyzing thematically was used in this study, specifically using the selective or highlighting approach. Van Manen (1990) describes the selective or highlighting approach, as one in 
which the researcher will "listen to or read a text several times, and ask, What statement(s) or phrase(s) seem particularly essential or revealing about the phenomenon or experience being described?" (p. 93). This approach allows for multiple themes per interview, while still finding the essence of a phenomenon. This also allows for what Lanigan (1988) described as "reflecting on the parts of the experience that have cognitive, affective, and conative meaning, and systematically imaging each part as present or absent in the experience" (p. 10), in order to determine the essential components of the experience.

For this process, the researcher examined the transcriptions to identify themes within each interview, and themes common among the interviews, using the process of horizonalization, in which each significant theme is listed with an equal level of importance (Creswell, 1998; Moustakas, 1994). The interview questions were designed based upon the review of literature, in order to focus the interviews on possible themes within the lived experiences of individuals participating in high school policy debate. The questions oriented the direction of the interviews, and some of the emerging themes mirror those shown by Littlefield (2001) and Fine (2001).

After the process of horizonalization of the common themes within the fifteen interviews, the second phase of analysis involved review of each transcript and the themes it contained, creating meaning units that described the essence of the phenomena (Creswell, 1998; Moustakas, 1994; Van Manen, 1990). This process involved reduction and elimination of themes that were not essential to the experience, themes expressed by fewer than one third of the sample, and taking the remaining themes and clustering them 
into the core themes of the experience (Moustakas, 1994). These themes lead to the descriptions presented within Chapter 4. Specific data from interviews were chosen in order to illuminate the lived experience of each theme. From further analysis of these themes, an overarching theme emerged, based upon the shared experience of the participants. 


\section{Chapter 4: Description of the Sample and Initial Thematization}

\section{The Description of the Sample}

The participants in the study graduated between 2003 and 2010. During the recruitment phase of the study, no potential participants who graduated in 2001, 2002, or 2011 emerged. The only graduation year not represented in the time period between 2003 and 2011 was 2008. There were eleven male participants, and four female participants. Anecdotally, as a coach, I observe more male than female participants in Policy Debate; at the OSAA Speech and Debate State Championship in 2012, none of the members of the top four teams in Policy Debate were female (Oregon State Activities Association, 2012). This may be due to the norms that Fine (2001) observed in his study of debaters in Minnesota, as he noted, "more to the point is the normal use of gender in the round. Being male is unmarked; being female is notable" (p. 111). Each student has been assigned a number (Student 1, Student 2, etc.), in order to not trivialize their experiences through the designation of pseudonyms. Likewise, the high schools involved have been assigned a letter (High School A, High School B, etc.) to distinguish them. Four participants attended the same high school, and two attended a second high school; the remaining participants are all from different schools. Table 2 provides a complete list of participants, schools, and years in high school, using the previously described pseudonyms.

Student 1 graduated from High School D, in 2006. This student competed in both Policy Debate and Public Debate, a form of parliamentary debate, during his high school career, competing in one or other during the entire four years, with a focus on Policy 
Debate during his junior year. After high school, he continued to be involved in the high school speech and debate community as a coach and a judge. He first became involved in Policy Debate because of his exposure to it in Speech class at his high school. He enjoyed his participation in Policy Debate, but did not place at the OSAA Speech and Debate State Championship tournament or qualify for the National Forensic League National Tournament in this event.

Student 2 graduated from High School H in 2009. This student also began his speech and debate career competing in Public Debate, but moved over to Policy Debate at the beginning of his sophomore year because he had a friend who wanted to try it, and his coach thought that he would be good at it. He competed in Policy Debate during his sophomore, junior, and senior years. He placed at the OSAA Speech and Debate State Championship tournament during his sophomore year, won the OSAA Speech and Debate State Championship tournament during his junior year, and qualified for the National Forensic League National Tournament during both his junior and senior years.

Student 3 graduated from High School K in 2010. He went to an initial meeting about the speech and debate team where he was given a list of events available and decided that he would like to do Policy Debate. He competed in it for the first three years of high school, until his partner graduated. After that, he competed in Public Forum Debate, qualifying to the National Forensic League National tournament during his senior year.

Student 4 graduated from High School C in 2006. She also began her speech and debate career competing in Public Debate, but switched over to Policy Debate at the 
beginning of her junior year because her team had a coach specifically for Policy Debate. She competed in Policy Debate in college, as well as competing in parliamentary debate. Student 5 graduated from high school in 2007, attending High School C for his freshman and sophomore years. Student 5 had moved from another state just before high school, where he competed in speaking events in middle school, the only one of the participants to mention involvement in public speaking prior to high school. Arriving in Oregon, he sought out the speech and debate team due to his prior experience. After his sophomore year, Student 5 moved out of state, and only continued competing for about half a year more, not competing at all during his senior year. Student 5 was very successful in individual events, placing in Impromptu speaking at the OSAA Speech and Debate State Championship tournament during his sophomore year.

Student 6 graduated from High School G in 2009. He competed all four years in Policy Debate, placing second at OSAA Speech and Debate State Championship tournament during his junior year, and winning the OSAA Speech and Debate State Championship tournament his senior year. He also qualified for the National Forensic League National Tournament during his junior and senior years. Student 6 became involved in Policy Debate through taking speech electives during his freshman year.

Student 7 graduated from High School A in 2003, making him the oldest of the participants. He became involved in Policy Debate because it was a respected event on his team, and he knew other students who competed in the event. He eventually switched over to Lincoln Douglas values debate because it allowed him to focus on more philosophical argument, and it also allowed him to work alone, matching his skills 
against his opponent's, rather than relying on a partner. Student 7 noted the significant differences in debating before and after September 11, 2001, something that none of the other participants mentioned.

Student 8 graduated from High School E in 2007, where he competed in Policy Debate during his freshman, sophomore, and senior years. He spent his junior year abroad, and so did not compete that year. He became involved with the activity after the speech and debate team from High School E visited his middle school during eighth grade. He was initially drawn to one of the speaking events, but soon found that Policy Debate might be something that he would enjoy. He competed in parliamentary debate in college, and currently is a high school speech and debate coach.

Student 9 did not graduate from high school, instead getting her GED. She attended High School B, and competed in Policy Debate during her sophomore and junior years. After a year and half, she quit Policy Debate, due to her lack of success in comparison to her other speaking events. However, she continued to be involved in other speech events, and is supportive of Policy Debate as a valuable activity for students.

Student 10 graduated from High School B in 2004. He competed in Policy Debate all four years, placing at the OSAA Speech and Debate State Championship tournament during his junior year and winning the tournament during his senior year. He also qualified to the National Forensic League National Tournament both his junior and senior years. He debated in college, both in Policy Debate and parliamentary debate, and he currently is a speech and debate coach, both at the high school and college level. 
Student 11 graduated from High School F in 2007. He competed for four years in Policy Debate, three years in another state, with his final year at High School F. Student 11 originally got involved in Policy Debate because he wanted to pursue a career as a lawyer. During his senior year, he qualified for the National Forensic League National Tournament in Policy Debate, but also placed in Public Forum Debate at the OSAA Speech and Debate State Championship tournament.

Student 12 graduated from High School C in 2005. She competed in Policy Debate during her senior year, because her team had a coach specifically for Policy Debate. She continued competing in college, first in Parliamentary Debate, then in Policy Debate, ultimately quitting due to issues with the norms of the activity at the college level, including closed-mindedness to alternative perspectives.

Student 13 graduated from High School C in 2007. During his freshman year, he took a speech class in which extra credit was offered for competing on the speech team. He began by competing in individual events, but by the spring of his freshman year, he was involved in Policy Debate. He qualified to the National Forensic League National Tournament during his senior year. He continued to debate during college, first in Policy Debate, and then in Parliamentary Debate.

Student 14 graduated from High School I in 2009. He competed in Policy Debate during his freshman and sophomore years, switching to Lincoln Douglas Debate during his junior year because his Policy Debate partner had graduated. He and his partner won the OSAA Speech and Debate State Championship tournament in Policy Debate during his sophomore year. During his junior year, he placed fifth in Foreign Extemporaneous 
Speaking at the National Forensic League National Tournament. After reaching that level of success, Student 14 decided not to compete during his senior year, and he has never competed in any form of speech or debate since.

Student 15 graduated from School J in 2010, where she competed in Policy Debate during her junior and senior years. During her sophomore year, she watched the final round of the Policy Debate at the OSAA Speech and Debate State Championship tournament and decided that she was interested in trying the activity. She also competed in Extemporaneous Speaking, attending the National Forensic League National Tournament in Foreign Extemporaneous Speaking during her senior year.

\section{Initial Themes}

From the initial data reduction, certain themes that intertwined throughout the interviews emerged. These initial themes "are not objects or generalizations; metaphorically speaking they are more like knots in the webs of our experiences, around which certain lived experiences are spun and thus lived through as meaningful whole" (Van Manen, 1990, p. 90). While there were differences in the manifestation of these themes, they were common to the lived experience of policy debate among the participants. Each theme is described, followed by specific data from the interviews following the method of Kapoor (1999), using quotes from the interviews to illuminate the lived experience of participants. The initial themes were establishing a knowledge base, effective use of communication skills, the ability to research, and development of confidence, with an overarching theme of political awareness, as shown in Figure 1. 


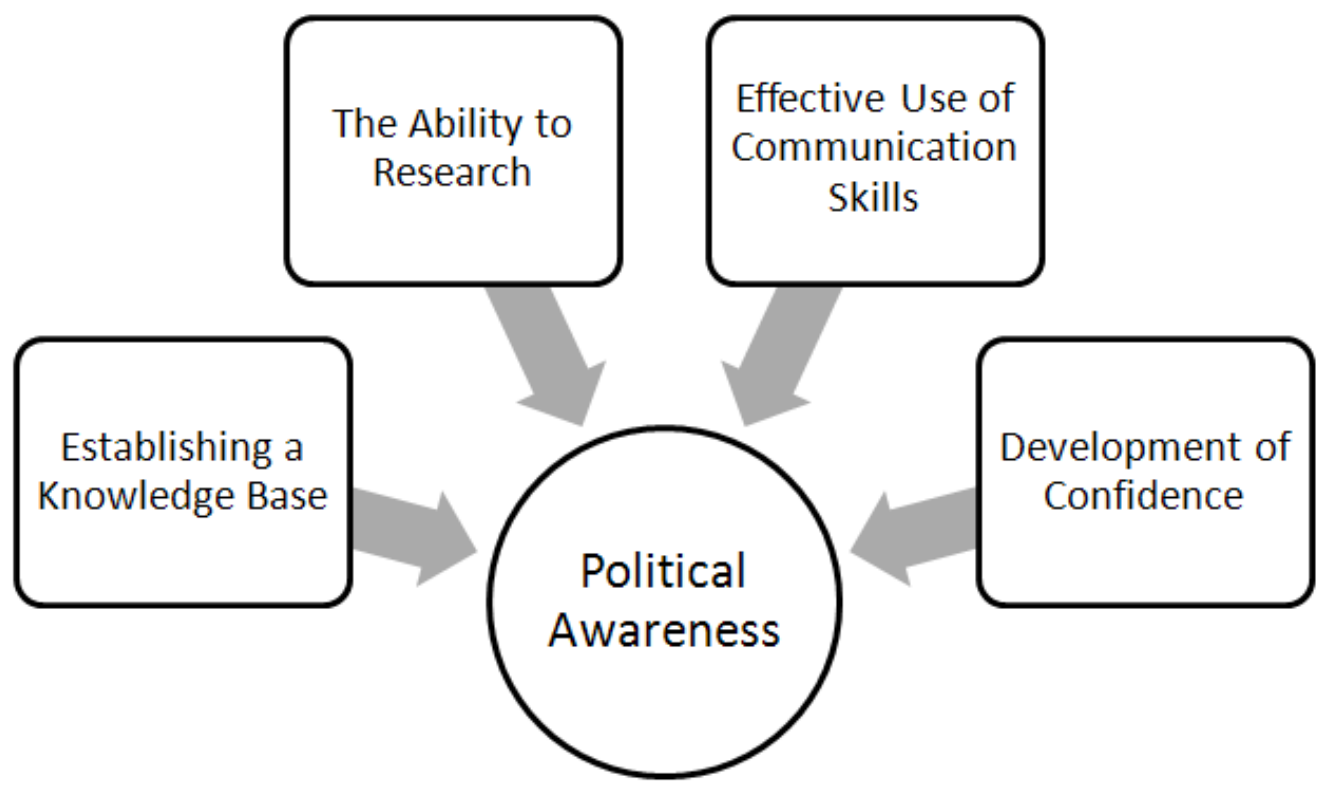

Figure 1: Initial Themes

\section{Theme One: Establishing a Knowledge Base}

Participants consistently referred to the way in which debate allowed them to gain a better understanding of the world beyond their own experience, a category that I would describe broadly as establishing a knowledge base. The knowledge that the participants gained through policy debate allowed them to have a better understanding of the world and provided a benefit within their academic studies. Littlefield (2001) observed that "debaters at the high school level learn a great deal about the topics that are selected for use during a particular school year" (p. 91). This knowledge is represented by both knowledge of the specific topics debated each year, but also knowledge of the way in which the political system in the United States works, and the way in which the United States' policy operates within the global community. Participants discussed this 
awareness in two main ways, in terms of the growth in their own knowledge, and the perspective that they gained from their increased knowledge base in comparison to their peers.

One of the topics that many students discussed in relation to the growth of their own knowledge was the topic, "Resolved: The United States federal government should substantially increase its public health assistance to Sub-Saharan Africa." On this topic, students gained knowledge about the political and social issues affecting Sub-Saharan Africa that they were not exposed to in any other aspect of their lives. A second topic that had a significant impact was "Resolved: That the United States federal government should establish a foreign policy substantially increasing its support of United Nations peacekeeping operations.” The quotes below elucidate the knowledge that students gained form these topics.

The Africa topic was definitely the start of a new passion of mine. SubSaharan Africa and the injustices that occur in Africa has definitely become kind of a passion of mine... When I got into college, I've taken classes on Africa, I'm going to go to Africa this summer, I want to join the peace corps and serve in Africa (Student 2, High School H).

I think that the perspective that the sex trafficking argument gave me... [was that] you can have somebody doing good things in the world and still have very serious negative implications (Student 8, High School E).

I definitely learned a lot that year about how the UN worked, how peacekeeping operations work, about multilateralism, and... international policy (Student 12, High School C).

[in response to the question, "Did running particular arguments have an effect on your personal beliefs or your perspective on the world?"] Yes. Especially with the sub-Saharan Africa topic. Running the global gag rule... I didn't even know that that was thing that we did... And I was not even close to aware of the number of human rights issues that were going on in sub-Saharan Africa before debate (Student 3, High School K). 
This knowledge base provided students with not only knowledge on the specific topics on which they had debated, such as aid to sub-Saharan Africa or United Nations peacekeepers, but also a broader knowledge of political issues. This broader knowledge provided a basis for examining the world beyond the self, continually adding more knowledge and perspective to the original knowledge base. Additionally, since debate requires arguing both sides of an issue, this also provides the opportunity to develop knowledge based on multiple perspectives. Students 13 and 4 both noted their perceptions of the differences in knowledge between debaters and non-debaters.

I noticed, more than anything, the sort of education I was getting... the really extreme nitty-gritty involvement in issues, in public affairs issues... people just weren't aware of... international politics, or history, or domestic politics to the extent that I was (Student 13, High School C).

[In response to the question, "What differences do you perceive between yourself and your classmates in high school who did not debate?" Oh, I think typically I thought that I was, I guess, smarter and more informed on current events for sure (Student 4, High School C).

This knowledge base provided the basis for understanding political and social issues of all types, not only those salient when debating. This knowledge base also overlapped with the ability to research, another emergent theme among the participants.

\section{Theme Two: Effective Use of Communication Skills}

Being able to communicate appropriately for an audience, either verbally or in writing was an important effect of participation in debate for many of the competitors, as was the ability to identify and analyze the way in which the presentation of ideas affects the way that the message is received. This echoed Fine's (2000) analysis that "debate 
serves as a technique for knowing in a world in which truth is not transparent but depends on the skills of its presenter" (p. 121). These skills, both in terms of writing and speaking, have served the participants well both in college and the workplace, as it allowed them to use their knowledge of constructing arguments, deploying evidence, and organizing ideas.

When I was in college, I'd just consistently get top marks on my essay writing... And I realized... my essays were good because they sounded like someone making a reasoned argument, like as if I had been giving a speech. And to me that made a lot of sense... I knew how to make arguments sound good when you're speaking out loud. (Student 5, High School C).

I would say that every single paper that I write in college is structured like an argument... within each paragraph is supporting evidence, followed by analysis, supporting evidence, followed by analysis, and then I ultimately draw some kind of conclusion... Which is not how some of my... peers write their papers. They don't really seem to get the argument part of it, which is kind of the whole point (Student 6, High School G).

How to structure an argument has definitely been useful for everything else [academic, outside of debate]...writing papers, etc. (Student 4, High School C).

It also honed their ability to read non-verbal expressions of their audience, and

find ways to change course in their presentation, in either communication style or content, based upon the responses they observed.

You get to know your audience. You figure out in order to win and impress someone and leave an impression... how do you change your speech? How do you change your language? How do you make a concept clear to someone who may have never heard about it? ... being able to explain these things and make them sound reasonable so that people can hold it in the palm of their hand, you know that's pretty challenging (Student 14, High School I).

It definitely has affected the way... that I interpret how other people are responding to what I say. Fortunately for me, the one saving grace was 
that I debated with my head up [as opposed to looking down at the evidence all the time] more often than with my head down, so I could see how people were acting, and how they thought, and that has definitely informed the way that I communicate with people now. To try to read nonverbal communication constantly (Student 10, High School B).

I talk fast, so people read that as being nervous...so I could read someone and say okay, it looks like he's upset that I'm talking so fast, I need to slow down. Or these people look confused, I need to slow down, cause I know it's really fast. So, I'd say... just being able to read people, being able to understand people's facial expressions, moods, attitudes, you can see into people if you really see that kind of stuff (Student 2, High School $\mathrm{H})$.

Being able to think on my feet and re-tailor an argument to a particular audience is probably the biggest skill and it's one...I use on a day to day basis in advocacy.. figuring out when...[a] legislator is not being persuaded by this argument, figuring out which information is actually going to move them at the drop of a hat has been really extremely useful (Student 1, High School D).

Being able to communicate ideas effectively, verbally or in writing, provided the opportunity for students to express themselves in a way that others could comprehend easily. The ability to disseminate ideas effectively, as much as having a knowledge base, is an important skill in academia, the workplace, and every day life.

\section{Theme Three: The Ability to Research}

In order to prepare affirmative and negative arguments, students who do Policy Debate do a significant amount of research, a common theme among the participants in this study. This theme is similar to establishing a knowledge base, but instead of the actual knowledge being the focus, the ability to use research tools effectively to garner knowledge was the focus of the participants' experiences, echoing similar observations by Fine (2001). For many of them, the ability to find information was nearly an end in 
itself, especially as they gained insight into comparing the quality of sources. Several observed that having already developed strong research habits was atypical in comparison to most high school students, as many comparably educated peers had not had the opportunity to learn how to use academic databases, such as Lexis-Nexis.

I remember when I was a freshman in high school... I would spend all my free time in the library. I would read news sources and print out news sources. I drove the school librarian crazy because I filled... tubs of information, and...I just got so much smarter. At one point I could name... the five parliamentary figures in Nepal, and...I was just loving it (Student 14, High School I).

I went into college and I knew how to use JSTOR and that was a huge boost for all of my behaviors... my freshman year, before anyone realized there was this wide world of academic databases, I just sat there during the first week of orientation geeking out over the fact that I had EBSCO, I had JSTOR and all the American Anthropological Association journals... being able to actually go through a database and pick out relevant information was a huge boon. And I still do that to some extent... find relevant information, discern things that are probably either too biased or don't have the right kind of information, and then incorporate those into my work. I write a lot of position papers, so it's a really nice skill to have (Student 1, High School D).

It's also what taught me to take sources seriously... By the time I got to college, and blogs have become so prevalent that they cover every major issue, you could write a whole college paper just with blogs as sources, but the reputability of the sources, and if could come under attack, is something that's always on your mind if you're looking for debate research. It's just totally invaluable, not only the ability to find them [sources], but the ability to know what goes into a good one (Student 8, High School E).

Primarily, it's taught me to not just pick one source and go with it, particularly on current events... when I'm researching I typically try to get sources...that are contrary to my own beliefs especially... You can say, that doesn't sound right to me and go back and check it or you can challenge something... I hadn't thought about it that way before (Student 3, High School K). 
I got to research in depth very specific subjects that I would have never researched otherwise in school... I definitely think that it helped me be a more well-rounded researcher... [and] find validity of arguments and facts that people were producing on the internet that I was reading for college (Student 9, High School B).

It definitely impacted the way that I take notes about readings, because I'll sort of make tags for different things, different paragraphs... so that when I reference it again, I know what I'm looking at... I don't have to read the whole page to know what it's about (Student 12, High School C).

I would use... what a lot of people use, like Lexis-Nexus Academic... like Google Scholar...we would go on different research databases... and then I would check to see if the sources were, you know, reliable...(Student 15, High School J).

I used a lot of the school resources, I used a lot of resources from friends or from acquaintances in college. Whether it's access to Lexis-Nexus, EBSCO... it was all about finding... the new search site... the new way to get the....accredited journals and things like that. It was just a matter of finding the best documentation you could to support your argument and where you could find it (Student 11, High School F).

I learned how to not only find articles with the tools that were becoming available... [debate] forced you to find innovative search tools and ways to find information, because you would win more... The other thing that it taught me to do was chase down footnotes in articles, because... [in] the footnotes of that argument would be where the person had written all the answers to that argument. So, it taught me to follow footnotes (Student 10, High School B).

The ability to research, coupled with the initial knowledge base and the ability to communicate effectively, provided students with the ability to learn more about the issues of interest to them, ranging from global to local issues. The ability to distinguish quality research sources, the ability to detect bias, and the ability to find a wide-reaching array of sources provided a basis for further academic study or pursuit of other issues of interest. 


\section{Theme Four: Development of Confidence}

Participants observed a connection between participation in Policy Debate and confidence, both positively and negatively. As Fine (2001) observed, "the debater conquers stage fright, feeling, like the actor, that public presentation is a peak experience" (p. 227). For many students, participation in Policy Debate gave them the confidence to be able to state their opinions in arenas beyond the debate round. However, for some, participating in such a competitive event with intelligent peers led to a decrease in self-confidence, as shown by the data from Student 9. The confidence instilled by Policy Debate also entrenched certain ideas about presentation and argumentation, as evidence by the data from Student 14 .

It made me realize that you don't have to feel confident to be confident (Student 3, High School K).

I think that I am sort of reserved in my response, but I'm also firm in my convictions now... I can take a step back and look at both sides but then come to a firm belief in what I think is right (Student 6, High School G).

But just knowing that it was okay to voice my opinion... realizing that just because you are in high school doesn't mean that you don't know more about a subject than an adult (Student 7, High School A).

There were many rounds that I would cry after because I thought I was so bad and so stupid, and... [it brings] up a lot of those issues when you lose debate rounds, because they're really intense and people get really emotionally invested in them (Student 9, High School B).

There's also a component where policy debate...reinforces that view...that anyone whose knowledge doesn't express itself in a certain kind of way doesn't know as much as you about it, so someone who can't... loudly declaim the policies of the Russian government with regards to manipulating fuel prices in eastern Europe is someone who doesn't really understand international politics, or foreign affairs or whatever (Student 13, High School C). 
The development of confidence can be both positive and negative, as it can create the space for self-expression, instill feelings of superiority in comparison to others, or introduce feelings of inferiority. For those who gained a voice, the development of confidence was a significant benefit, while for those whose confidence was eroded, participation in Policy Debate was a detriment. However, regardless of the feelings of inferiority after debating, the ability to stand up in front of others and make arguments is a facet of confidence in itself.

\section{Meta-theme: Political Awareness}

Participants observed that their involvement in Policy Debate lead to their continued interest and knowledge about political issues. For many, this interest and involvement stemmed from establishing a knowledge base and being able to research issues of importance. Continuing to know what was happening in the world, beyond the need to know about the world in a debate context, was a consistent theme. The participants were split between being overtly involved in politics, through activism, monetary contributions, or merely being aware, and being cynical about their ability to effect real change.

I'm kind of am a victim of my generation and we don't totally care as much about voting, but I think that I definitely am more involved in the news and more aware of what's going on, for example, in the Republican primaries right now than most people. I plan on voting (Student 6, High School G).

It made made me... a lot more analytical about politics... and just being aware of all the different ideas that are out there. I feel like a lot of the problem in the culture now is that people don't really know what's involved in a policy that they're backing, just that it's backed by... Republicans or Democrats... but they don't actually take a look into what's behind the policy. Which is to our detriment, I think... it definitely gave 
me kind of the sort of knowledge that I still want to stay on top of current events, to know what's going on in the world around me. A lot of people are just content not to do that; it's irresponsible (Student 5, High School C).

The discourse surrounding social services and the way social services were being constructed and the way that...it made certain assumptions about the poor, it established a very paternalistic relationship between the government... those who receive it [social services] (Student 15, School J).

If anything, it has made me just not [politically active]. I don't care... Nothing ever changes. And knowing... about a topic doesn't actually help you in any way. Talking to people who haven't researched stuff, just because you know an infinite amount about it, you can never convince someone that they are wrong (Student 7, High School A).

It's too easy to take a cynical, 'I can't believe any claim, I can't earnestly advocate for anything,' sort of approach, and want to tune out and drop out, when you think you know better than everyone else about what's going on...I've voted every year since I was eligible to vote, in every election, like local or national, and so maybe that's something (Student 13, High School C).

I did my senior seminar on registering to vote and... driving civic enrollment... I vote every election. I'm very involved in politics. You know, I'm not actively involved, I do donate. But it is something that is in the forefront of my mind, is how our government is affecting my daily life. You know, what, how does Barack Obama's health care policy impact me, which I'm insured until I'm 26, thankfully, now, so that's awesome... I'm much more conscious of government action, of worldview, things like that (Student 11, High School I).

All of the earlier themes converge around the overarching theme of political awareness. This awareness, bolstered by knowledge and research, was a common theme for all of the participants. Participation in high school Policy Debate helped them gain one or more of the tools needed to create this awareness, whether or not they opted to act upon their knowledge. This connects back to the ideas about 
democracy, inquiry, and the public sphere discussed by Freire, Dewey, Giroux, and Habermas. 


\section{Chapter 5: Discussion and Conclusion}

As referenced by the participants in this study, political awareness and activism is not perceived to be the norm among young adults. Currently, as the world faces political upheavals, such as the Arab Spring of 2012, continuing conflict as a result in the United States' War on Terror, and continuing domestic economic concerns in the United States, as evidenced by the Occupy movement, political awareness is more important than ever.

Freire (2006) argued that "in problem posing education, people develop their power to perceive critically the way they exist in the world with which and in which they find themselves" (p. 83). Through participation in competitive Policy Debate, students gain knowledge, communication skills, confidence, and an ability to research, all of which contributed to political awareness. The skills associated with the initial thematization connect directly with Dewey's idea of an emancipation of mind as a prerequisite for participation in democracy. Without a knowledge base, without the ability to gain knowledge through research, without the ability to communicate and understand communication, there would be no foundation for inquiry, the habit of mind considered necessary by Dewey within a democracy.

In Oregon, the number of participants in Policy Debate has dwindled over the last twenty years, due to the emergence of two new styles of debate, as well as other factors. However, as previously discussed, there are benefits to participation in the event. When asked to compare students who did not debate in high school to those who did, the participants observed that the global and political knowledge, the research skills, and the ability to communicate were stronger among those who debated. When asked to compare 
those students who did Policy Debate compared to other debate forms, the participants had some interesting observations. Student 1 observed

I would say folks who did LD [Lincoln Douglas Debate] were a lot better at making philosophical arguments... folks who did public

[Parliamentary-style Debate] were a lot better [at]... changing argumentation midstream, thinking on their feet. And then folks who did CX [policy debate] were a lot better prepared to use information to bolster a point (Student 1, High School D).

The research aspect of Policy Debate was reinforced by many participants, including Student 5, who observed, "the amount of research and preparation needed for CX debate, seems so much higher" when compared to other debate forms (Student 5, High School G). Student 4 observed that, in comparison to other styles of debate, students who participated in Policy Debate had to be "better prepared in making strategic decisions and in how arguments are structured" (Student 4, High School C). The emphasis on argument construction and choice is reinforced by Fine's (2000) discussion of why it is beneficial to debate both sides of a topic, as he noted

debating both sides of a case is valuable training for analyzing public policy, teaching respect for differing opinions, acquiring multiple perspectives, and emphasizing the dangers of absolutism (p. 114).

The ability to examine an issue from multiple perspectives, and the ability to understand the way that arguments are structured allows for dialogue, allowing for authentic interaction with others within the political sphere (Freire, 2006).

Debate culture, in particular policy debate culture, can be perceived to have negative effects as well. Student 14 observed that participation in debate entrenches ideas about being able to access and deploy knowing, noting that "you're not taught to have a lot of respect for someone who doesn't have a mile wide, inch deep ability to instantly 
make an argument" (Student 14, High School C). Debate also fosters competition rather than cooperation (Fine, 2001), as it naturally pits two sides against one another. It also can have the effect of eroding confidence, as well as increasing it, as shown in Chapter 4. As Muir (1993) acknowledged, debate "tends to overemphasize knowledge and tactics and downplay personal feelings" (p. 292).

Each of the aspects of the lived experience of high school Policy Debate in Oregon described in this study form a part of the characteristics needed to be an active participant in democracy and public discourse. Knowledge was considered the base of democratic participation by Dewey (Dewey, 1903; Geren, 2001). The ability to research allows for the furthering of knowledge, and leads to the desire for future knowledge. The ability to communicate, verbally or in writing allows for dialogue with others about issues of importance (Freire, 2006), while confidence gives the ability to express such communication. Political interest, knowledge, and involvement all stem from knowledge, research, and communication, allowing for the desire to participate, even from a place of cynicism, in dialogue with others. As Muir (1993) observed, debate is "intended to teach debaters to see both sides of an issue and to become proficient in the exposition of the argument independent of moral or ethical convictions" (p. 278). This ability to explain and understand both sides of an argument provides a basis for understanding multiple perspectives on an issue, increasing knowledge and the potential for discussion on a given issue, a discussion on the public sphere level.

When providing a description of public discourse, based upon both the ideas of Dewey and Habermas, Geren (2001) observed that 
public discourse, as a conceptually distinct communicative space, entails certain values: tolerance - both a tolerance of individual differences and a tolerance for frustration and ambiguity - in the search for the common good, diversity, community, reason, and critique (p. 198)

Participation in Policy Debate promotes the values of public discourse, and allows participants to garner the skills necessary to participate in such discourse. This study does not seek to infer that other forms of competitive high school debate cannot foster similar abilities in students; the examination of other forms of debate is best left for another research project. Rather, this study seeks to describe the ways in which the lived experience of Policy Debate has affected the lives of students who participated in the activity between 1999 and 2010 .

Kester and Booth (2010) observed that "Freire was firmly convinced that politics are at best subtly embedded within curriculum, and at worst malevolently injected into the system of education as a form of social control" (p. 501). Participation in high school Policy Debate provides the opportunity for students to explore politics based upon their own knowledge, research, and dialogue within the context of the debate round. Holboa (2008) noted that "in order to participate in a formal debate, students need to be knowledgeable of current and controversial issues, develop a textured understanding beyond the obvious issue, and be able to develop reasoning skills that focus on real issues" (p. 59). In a given debate, students may argue about the ways in which a United States governmental policy will affect the economy, relations with other nations, or the way that we treat individuals within our own nation. The opportunity to address these issues provides students with tools to analyze the political decisions of the actual government. The ability to use quality sources of information to expand knowledge 
provides students with the ability to consider issues from multiple perspectives. All of these tools are necessary in the process of becoming an informed citizen of the world. These tools allow for the manifestation of Habermas's idea that "communicative rationality at the level of the public sphere that reason can be used to solidify and enhance a democratic culture" (Whipple, 2005, p. 167).

Currently, we exist in a world fraught with war, economic decline, an increasing wide divide between political orientations, and an increasingly political disengaged population. In the post 9/11 world, Giroux (2003) observed, "increasingly, children seem to have no standing in the public sphere as citizens, and thus are denied any sense of entitlement and agency" (p. xiv). Participation in Policy Debate has given students the skills to gain the knowledge necessary to make informed decisions about their political choices, on the ballot and beyond the ballot, gaining the ability to take back their place in the public sphere. While not all have chosen to take their skills beyond becoming informed and voting, these abilities allow them to step up their participation in public discourse at any point. With the ability to research, with an understanding of the ways in which communicative choices can affect a message, and with the interest in maintaining knowledge of political issues, students who have participated in Policy Debate are steps ahead of their peers in their ability to participate as citizens.

\section{Limitations of the Study}

As this is a phenomenological study, in which participants were not selected at random, this study is not generalizeable for all participants in high school policy debate in Oregon. Participants chose to be interviewed for this study, which may have limited 
the participation of individuals with negative experiences, or individuals who were no longer invested in the speech and debate community. Other methods might have provided different information about competitors within policy debate. A survey could have reached a larger number of participants, allowing for greater variety within the responses. An ethnographic approach, such as the one used by Fine (2001), might have shown a different picture of a specific team over a shorter period of time.

\section{Potential Topics for Future Study}

This study had a smaller number of female participants than male participants, roughly proportional to the participation of each gender in Oregon. Future study might examine the lived experience of female participants in high school policy debate, in order to find potential additional themes within that lived experience. Also, since this study only focused on one age band of participants, future studies might examine other age bands and make comparisons between the lived experiences of different age bands, to elucidate the way in which Policy Debate has changed over time.

\section{Significance of the Study}

Participation in policy debate provides beneficial skills to students. This study is significant because it provides the opportunity for participants to reflect upon their experiences and express in their own words how they perceived their lived experience of high school policy debate. Other studies have provided statistical analysis of the benefits of participation (Littlefield, 2001), or have used ethnographic techniques to describe the debate community (Fine, 2001). This study is able to describe the experience using the words of the participants in the study, rather than creating a numeric picture of their 
experiences, or describing their experiences through participant observation, creating a document which can be used academically, but can also serve as a part of a discussion among members of the speech and debate community about the value of the activity. 


\section{References}

Allen, A. Berkowitz, S., Hunt, S., and Louden, A. (1999). A meta-analysis of the impact of forensics and communication education on critical thinking. Communication Education, 48, 18-30.

Aspers, P. (2009). Empirical phenomenology: A qualitative research approach (the Cologne seminars). The Indo-Pacific Journal of Phenomenology, 9(2), 1-12.

Barbour, R. S. (2008). Introducing qualitative research: A student's guide to the craft of doing qualitative research. Los Angeles, Calif: SAGE.

Chesebro, J. W., \& Borisoff, D. J. (2007). What makes qualitative research qualitative? Qualitative Research Reports in Communication, 8(1), 3-14.

Creswell, J. W. (1998). Qualitative inquiry and research design: Choosing among five traditions. Thousand Oaks, Calif: Sage Publications.

Dam, G. T. \& Vollman, M. (2004). Critical thinking as a citizenship competence: teaching strategies. Learning and Instruction 14, 359-379.

Dewey, J. (1903). Democracy in Education. The Elementary School Teacher, 4(4), 193204.

Deyer, S. (2004). Evaluating Scarcity Beyond the Forensic Experience: Alumni Perspectives. The Forensic of Pi Kappa Delta, 89, 15-24.

Edwards, R. E. (2008). Competitive debate: The official guide. New York: Alpha.

Edwards, R. E., \& National Federation of State High School Associations. (1992). A glossary of terms for Policy Debate. Kansas City, Mo: B. Durbin. 
Ericson, J. M., Murphy, J. J., \& Zeuschner, R. F. (2003).The debater's guide. Carbondale: Southern Illinois University Press.

Fine, G. A. (2000). Games and truths: Learning to construct social problems in high school debate. The Sociological Quarterly, 41(1), 103-123.

Fine, G. A. (2001). Gifted tongues: High school debate and adolescent culture. Princeton, N.J: Princeton University Press.

Fleming, D. (1998). Rhetoric as a Course of Study. College English, 61(2), 169-191.

Freire, P. (2006). Pedagogy of the oppressed. New York: Continuum.

Geren, P. R. (2001). Public Discourse: Creating the Conditions for a Dialogue Concerning the Common Good in a Postmodern Heterogeneous Democracy. Studies in Philosophy and Education, 20, 191-199.

Giroux, H. (1997). Pedagogy and the politics of hope: theory, culture, and schooling: a critical reader. Boulder, CO: WestviewPress.

Giroux, H. (2003). The abandoned generation: democracy beyond the culture of fear. New York: Palgrave Macmillan.

Greenstreet, R. (1993). Academic Debate and Critical Thinking: A Look at the Evidence. National Forensic Journal, 11 (1), 13-28.

Hanes, T. R. (2007). Debating Policies: The skills and theories of Cross-Examination and Public Forum debate. Retrieved from http://www.nflonline.org/uploads/Main/hanescxpfdebate.pdf.

Hanson, J. (1990). NTC's Dictionary of Debate. Lincolnwood, IL: National Textbook Company. 
Hein, S. F., \& Austin, W. J. (January 01, 2001). Empirical and hermeneutic approaches to phenomenological research in psychology: a comparison. Psychological Methods, 6, 1, 3-17.

Holba, A. (2008). Revisiting Cicero in Higher Education Cultivating Citizenship Skills through Collegiate Debate Programs. Speaker \& Gavel, 45, 52-61. Accessed at http://www.mnsu.edu/cmst/dsr-tka/vol45_2008/vol45-2008.pdf

Kapoor, P. (1999). “A chance of double lives": phenomenological study of black female graduate experience. In T. A. McDonald \& T. Ford-Ahmed (Eds.), Nature of a sistuh: Black women's lived experiences in contemporary culture (pp. 53-70). Durham, N.C: Carolina Academic Press.

Kennedy, G. A. (2007). Aristotle: On Rhetoric ( $2^{\text {nd }}$ edition). New York: Oxford University Press.

Kester, K., \& Booth, A. (December 01, 2010). Education, peace and Freire: A dialogue. Development, 53, 4, 498-503.

Lanigan, R. L. (1988). Phenomenology of communication: Merleau-Ponty's thematics in communicology and semiology. Pittsburgh, PA: Duquesne University Press.

Lanigan, R. L (1994). Capta versus data: Method and evidence in communicology. Human studies, 17 (1), 109-130.

Littlefield, R. S. (2001). High school student perceptions of the efficacy of debate participation. Argumentation \& Advocacy, 38(2), 83-97.

Maxwell, J. A. (2005). Qualitative research design: An interactive approach. Thousand Oaks, Calif: Sage Publications. 
Mitchell, G. R. (December 07, 1998). Pedagogical Possibilities for Argumentative Agency in Academic Debate. Argumentation and Advocacy, 35, 2, 41-60.

Moran, D. (2000). Introduction to phenomenology. London: Routledge.

Morrow, R. A., \& Torres, C. A. (2002). Reading Freire and Habermas: Critical pedagogy and transformative social change. New York: Teachers College Press

Moustakas, C. (1994). Phenomenological research methods. Thousand Oaks, CA: Sage.

Muir, S. A. (1993). A defense of the ethics of contemporary debate. Philosophy and Rhetoric, 26 (4), 277-295.

National Forensic League. (n.d.). NFL History: A Rich Tradition of Training Youth for Leadership. Retrieved from http://www.nflonline.org/AboutNFL/YearbyYear.

Nelson, J. L. (1987). Critical Response: On Media and Existence. Critical Studies In Mass Communication, 4(3), 311-318.

Nelson, J. L. (1986). "Television and its audiences as dimensions of being: Critical theory and phenomenology". Human studies, 9(1), 55-69.

Nelson, J. L. (1989). "Phenomenology as feminist methodology: explicating interviews." In K. Carter \& C. Spitzack (Eds), Doing research on women's communication: Perspectives on theory and method. Norwood, N.J: Ablex Pub. Corp.

Oregon Schools Activities Association (2012). 2012 Speech State Championships Final Results. Retrieved from http://osaa.org/speech/2012/12results.pdf. 
Paterno, Jim (1994). The critique: An explanation, examination, \& evaluation. Rostrum, $68(9)$.

Patton, M. (2002). Qualitative Research \& Evaluation Methods 3rd Edition. Thousand Oaks, CA: Sage

Polkinghorne, D. (January 01, 2007). Validity Issues in Narrative Research. Qualitative Inquiry, 13, 4, 471-486.

Richards, L. (2009). Handling qualitative data: A practical guide. London: SAGE.

Roberts, P. (March 01, 1999). A Dilemma for Critical Educators? Journal of Moral Education, 28, 1, 19-30.

Rogers, J. (2005). Graduate school, professional, and life choices: An outcome assessment confirmation study measuring positive student outcomes beyond student experiences for participants in competitive intercollegiate forensics. Contemporary Argumentation and Debate 26, 13-40.

Shelby, A. N. (1986). "The Theoretical Bases of Persuasion: A Critical Introduction". The Journal of business communication, 23 (1), 5-29.

Snider, A. C. (2008). The code of the debater. New York: International Debate Education Association.

Tumposky, N. R. (2004). The debate debate. The Clearing House, 78 (2), 52-55.

Turner, M., Yao, S., Baker, R., Goodman, J., and Materese, S. (2010). Do lay people prepare for both sides of an argument? The effects of confidence, forewarning, and expected interaction on seeking out counter attitudinal information. Argumentation and Advocacy, 46, 226-239.

Van Manen, M. (1990). In Researching lived experience: Human science for an action sensitive pedagogy. Albany, N.Y.: State University of New York Press. 
Waite, C. (2007). On the evolution of a discipline. Qualitative Research Reports in Communication, 8(1), 15-19.

Whipple, M. (2005). The Dewey-Lippmann Debate Today: Communication Distortions, Reflective Agency, and Participatory Democracy. Sociological Theory, 23(2), 165-178.

Winkler, C., Newnam, W., and Birdsell, D. (1993). Lines of argumentation. Madison, Wisconsin: WCB Brown and Benchmark Publishers. 


\section{Appendix A: Informed Consent}

You are invited to participate in a research study conducted by Ameena Amdahl-Mason from Portland State University, Communication Studies. The researcher hopes to learn about your experience will high school Policy Debate in Oregon. You were selected as a possible participant in this study because you were a former competitor in Policy Debate between the ages of eighteen and twenty-eight.

If you decide to participate, you will be asked to complete an audio-recorded interview. While participating in this study, it is possible that you will need to meet with the researcher outside of your normal coaching commitment. You may not receive any direct benefit from taking part in this study, but the study may help to increase knowledge that may help others in the future.

Any information that is obtained in connection with this study and that can be linked to you or identify you will be kept confidential. However, it will not be anonymous. Your identity will be kept confidential by the use of pseudonyms for all schools and participants within the thesis itself. If you are interviewed, the audio-recordings will be stored in a password protected mp3 file for two years, and then will be destroyed.

Your participation is voluntary. You do not have to take part in this study, and it will not affect your relationship with Portland State University or Ameena Amdahl-Mason. You may also withdraw from this study at any time without affecting your relationship with Portland State University or Ameena Amdahl-Mason.

If you have concerns or problems about your participation in this study or your rights as a research subject, please contact the Human Subjects Research Review Committee, Office of Research and Sponsored Projects, 600 Unitus Bldg., Portland State University, (503) 725-4288 / 1-877-480-4400. If you have questions about the study itself, contact Ameena Amdahl-Mason at 7502 SW Barnes Rd. \#C, Portland, OR 97225 or at (503) 913-7125.

Your signature indicates that you have read and understand the above information and agree to take part in this study. Please understand that you may withdraw your consent at any time without penalty, and that, by signing, you are not waiving any legal claims, rights or remedies. The researcher will provide you with a copy of this form for your own records.

Signature

Date

Printed Name 


\section{Appendix B: Introductory Email}

Dear [prospective subject's name]:

My name is Ameena Amdahl-Mason, and I am a graduate student at Portland State

University. I am beginning a study on high school Policy Debate in Oregon, and would like to invite you to participate.

You are being asked to take part because you are a former high school Policy Debater between the ages of eighteen and twenty-eight. As part of the study, I am interested in your opinions and attitudes about your experiences as a high school Policy Debater in Oregon. If you decide to participate, you will be asked to schedule an interview with me, which will involve answering questions about your experiences with high school Policy Debate. It should take approximately one to two hours to complete.

As a result of participation in this study, you may re-live some of the ups and downs of competition in high school Policy Debate. However, I assure you that if, at any time, you no longer wish to be interviewed, you may opt-out of the study. You may not receive any direct benefit from taking part in this study, but the study may help to increase knowledge that may help others in the future.

Any information that is obtained in connection with this study and that can be linked to you or identify you will be kept confidential. Subject identities will be kept confidential through the use of pseudonyms in the transcribing process and through secure storage of the audio recordings of the interviews.

Participation is entirely voluntary. Your decision to participate or not will not affect your relationship with the researcher or with Portland State University in any way. If you decide to take part in the study, you may choose to withdraw at any time without penalty. Please keep a copy of this letter for your records.

If you have concerns or problems about your participation in this study or your rights as a research subject, please contact the Human Subjects Research Review Committee, Office of Research and Sponsored Projects, 600 Unitus Bldg., Portland State University, (503) 725-4288 / 1-877-480-4400. If you have questions about the study itself, contact Ameena Amdahl-Mason at 7502 SW Barnes Rd. \#C, Portland, OR 97225 or at (503) 913-7125 Sincerely,

Ameena Amdahl-Mason

Portland State University 


\section{Appendix C: Interview Questions}

Due to the nature of phenomenological research, the goal of which is to understand the lived experience of the interviewee, the questions may vary based upon the particular conversation. When using phenomenological interviewing, it is not necessary to ask each interviewee the same set of questions.

1. How did you become involved in policy?

2. Describe the types of arguments that you often ran in Policy Debate rounds.

a. Describe some of the philosophical positions that you ran.

b. Describe some of the policy-based positions that you ran.

c. How did you pick the type of arguments you ran?

d. Did running particular arguments have an effect on your personal beliefs/perspective on the world?

3. Which arguments did you work the hardest on, and which are the most effective?

a. How did surprise or unpredictability factor into this?

b. How did winning factor into this?

c. Which arguments did you run the most consistently? Why?

d. Were you able to use arguments or ideas from Policy Debate in your life outside of debate, academically or socially?

4. Describe your research practices in Policy Debate.

a. How did you divide the research burden?

b. Describe your practices for philosophical research.

c. Describe your practice for policy-based research.

d. What factors affected the depth and breadth of your research?

e. Have debate research practices had an effect on the way that you research in an academic setting, or in the way that you research other issues that are important to you?

5. How would you describe a typical Policy Debate round?

a. How did you and your partner decide on the positions to run?

b. What in round adaptations did you find yourself using?

c. What would make a round unusual or atypical for you?

d. How did the critic's paradigm affect the round?

e. Are there ways that adaptation in a debate round has had an effect on your communication choices in other settings?

6. What differences do you perceive between yourself and your classmates in high school who did not debate?

a. ...differences between debate and mock trial?

b. ...debate and constitution team?

c. ...debate and student council?

d. ...Policy Debate and other forms debate?

7. What aspects of Policy Debate lead to your continued interest (or eventual disinterest)?

a. What effects does participation in Policy Debate have on your post-high school life?

b. Do you/did you debate in college? 
c. How do/did you use your experience in college or in your work life?

d. What effect has debate had on your civic involvement, either in social or political issues?

e. If you do not see any effects, why do you think that is? 


\section{Appendix D: Topics Debated Between 1999-2010}

1999-2000

Resolved: That the federal government should establish an education policy to significantly increase academic achievement in secondary schools in the United States.

2000-2001

Resolved: That the United States federal government should significantly increase protection of privacy in the United States in one or more of the following areas: employment, medical records, consumer information, search and seizure.

2001-2002

Resolved: That the United States federal government should establish a foreign policy significantly limiting the use of weapons of mass destruction.

2002-2003

Resolved: That the United States federal government should substantially increase public health services for mental health care in the United States.

2003-2004

Resolved: That the United States federal government should establish an ocean policy substantially increasing protection of marine natural resources.

2004-2005

Resolved: That the United States federal government should establish a foreign policy substantially increasing its support of United Nations peacekeeping operations.

2005-2006

Resolved: The United States federal government should substantially decrease its authority either to detain without charge or to search without probable cause.

2006-2007

Resolved: The United States federal government should establish a policy substantially increasing the number of persons serving in one or more of the following national service programs: AmeriCorps, Citizen Corps, Senior Corps, Peace Corps, Learn and Serve America, Armed Forces.

2007-2008

Resolved: The United States federal government should substantially increase its public health assistance to Sub-Saharan Africa.

2008-2009

Resolved: The United States federal government should substantially increase alternative energy incentives in the United States. 
2009-2010

Resolved: The United States federal government should substantially increase social services for persons living in poverty in the United States. 